\title{
Derivation of soil thresholds for arsenic applying species sensitivity distribution
}

\author{
C.F. Ding \& X.X. Wang \\ Key Laboratory of Soil Environment and Pollution Remediation, Institute of Soil Science, \\ Chinese Academy of Sciences, Nanjing, P.R. China
}

\begin{abstract}
It is essential to establish an accurate soil threshold for the implementation of soil management practices. This study takes root vegetable as an example to derive soil thresholds for arsenic (As) based on the food quality standard using species sensitivity distribution (SSD). A soil type-specific bioconcentration factor (BCF, ratio of As concentration in plant to that in soil) generated from soil with a proper As concentration gradient was calculated and applied in the derivation of soil thresholds instead of a generic BCF value to minimize the uncertainty. The derived soil thresholds were dependent on the combination of soil $\mathrm{pH}$ and iron oxide $\left(\mathrm{Fe}_{\mathrm{OX}}\right)$ content.
\end{abstract}

\section{INTRODUCTION}

Generally, soil thresholds are calculated from the maximum levels for potentially toxic elements in food products for the various crops and the soil-plant transfer model (de Vries \& McLaughlin, 2013). The food quality standards (FQSs) for contaminants are set according to different food categories, such as cereals, leafy vegetables, root vegetables, fruits, beans, nuts, etc. (Shao et al., 2014). However, the current soil quality standards (SQSs) of potentially toxic elements used for agriculture in many countries around the world do not consider the diverse crop species and cultivars and the effects of soil properties, and therefore may be either over- or under-conservative, resulting in unnecessary economical or ecological costs (Recatalá et al., 2010; Zhao et al., 2015). Therefore, it is urgent to revise and improve the SQSs.

Species sensitivity distributions (SSDs) are commonly used to derive threshold values for contaminants. After estimation of the SSD parameters using statistical extrapolation methods, a hazard concentration from the fifth percentile of the distribution (HC5) is calculated. The HC5 is the concentration at which less than $5 \%$ of the species within an ecosystem is expected to be affected and is often used for deriving environmental quality standards (Korsman et al., 2016). Very few studies have applied the SSD methodology to derive soil thresholds for As due to the lack of data generated from different crop species and different soil types.

Therefore, with a focus on widely consumed root vegetables, this study aims to derive soil thresholds for As based on the food quality standard using SSD method.

\section{PROCEDURE AND METHODS}

\subsection{Framework for deriving soil thresholds for As}

In brief, the procedures of deriving soil thresholds for As included, first, the investigation of the sensitivity distributions of different vegetable cultivars for accumulating As. The second step is the construction of the prediction model for As transfer from soil to vegetable. The third step is the verification of crossspecies extrapolation of the prediction model and the normalization of As bioaccumulation data. Finally, the SSD curves were constructed and HC5 values were calculated, and then the prediction model for HC5 was developed as a function of soil properties.

\subsection{Investigation of sensitivity distributions and development of prediction model}

A total of twenty-one soils covering a wide variation in soil properties were collected throughout China. Firstly, two typical soils, an acidic Ferralsols (pH 4.84) and a neutral Cambisols ( $\mathrm{pH}$ 6.93), were used to test the sensitivity variations of different cultivars for accumulating soil As. Three species of root vegetables, radish (Raphanus sativus L.), carrot (Daucus carota L.), and potato (Solanum tuberosum L.) were used in the experiment; four representative cultivars of each species were selected. Then, to minimize the effect of soil properties on the bioaccumulation data, the soil-plant transfer model was developed and used as the normalization relationship from carrot cultivar New Kuroda grown in the twenty-one soils. Uncontaminated soils were spiked with soluble As salt $\left(\mathrm{Na}_{3} \mathrm{AsO}_{4} \cdot 12 \mathrm{H}_{2} \mathrm{O}\right)$. 

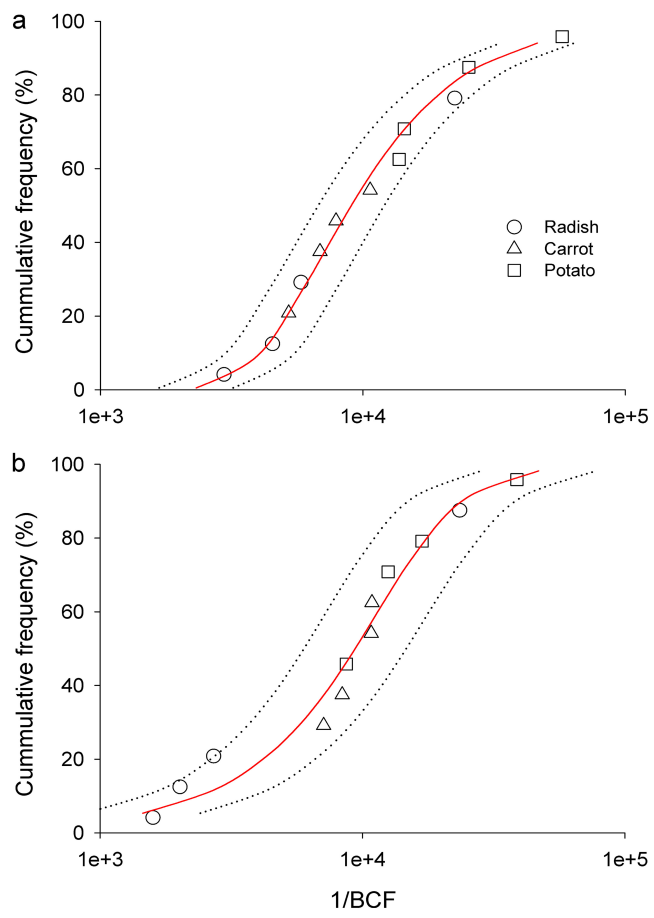

Figure 1. Species sensitivity distributions of the twelve vegetable cultivars grown in Ferralsols (a) and Cambisols (b) fitted by Burr Type III distribution.

Three treatments were applied, including the control, low-As (As1, 15-30 $\mathrm{mg} \mathrm{kg}^{-1}$ ), and high-As (As2, $30-60 \mathrm{mg} \mathrm{kg}^{-1}$ ). After aging for three months, vegetable plants were cultured under regular farming management style. Three replicates were tested per treatment.

\section{RESULTS AND DISCUSSION}

The SSD curves (Fig. 1) were constructed with Burr Type III distribution based on the accumulation data of different vegetable cultivars grown in Ferrosols and Cambosols. The geometric means of BCFs under three As treatments were calculated and taken to represent the sensitivity for the same vegetable cultivar. The SSD curves showed that the twelve vegetable cultivars exhibited sensitivity variations for As accumulation, with radishes and potatoes in both soils being the most and least sensitive, respectively.

The normalization relationship was shown as $\log [\mathrm{BCF}]=0.13 \mathrm{pH}-1.39 \log \left[\mathrm{Fe}_{\mathrm{OX}}\right]-1.98$ with $\mathrm{R}^{2}=0.67$. The model was subsequently used for normalizing all individual $\mathrm{BCF}$ values of the twelve cultivars cultivated in Ferralsols and Cambisols to soil conditions with different combinations of soil $\mathrm{pH}$ (4.5-9.0) and $\mathrm{Fe}_{\mathrm{OX}}\left(15-65 \mathrm{~g} \mathrm{~kg}^{-1}\right)$.

The critical soil concentration for each cultivar under different soil conditions after normalization was back calculated from the corresponding BCF value and the food quality standard of As $\left(0.5 \mathrm{mg} \mathrm{kg}^{-1}\right.$, fresh

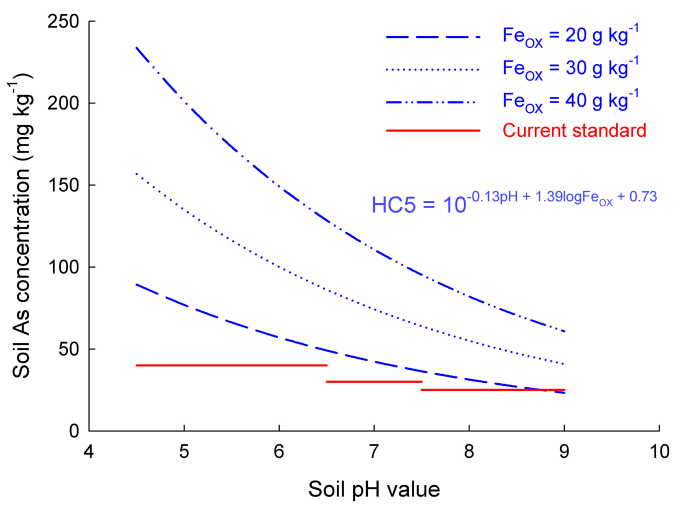

Figure 2. Comparison of the derived soil As thresholds with current Chinese soil quality standard.

weight). Then the hazardous concentrations (HC5) were calculated from the Burr Type III fitted SSD models. The calculation formula for $\mathrm{HC} 5$ was provided in Figure 2. The results suggested that the current SQS were only valid for soils with limited combinations of soil $\mathrm{pH}$ and $\mathrm{Fe}_{\mathrm{OX}}$ content.

\section{CONCLUSIONS}

This study adopted the SSD methodology to derive soil thresholds for As in view of the food quality standard while taking into account the influences of soil properties. The approach proposed here is widely applicable to other crops as well as other trace elements that have the potential to cause food safety issues.

\section{ACKNOWLEDGEMENTS}

This work was supported by the National Key Research and Development Program of China (2016YFD0800400).

\section{REFERENCES}

de Vries, W. \& McLaughlin, M.J. 2013. Modeling the cadmium balance in Australian agricultural systems in view of potential impacts on food and water quality. Sci. Total Environ. 461-462: 240-257.

Korsman, J.C., Schipper, A.M. \& Hendriks, A.J. 2016. Dietary toxicity thresholds and ecological risks for birds and mammals based on species sensitivity distributions. Environ. Sci. Technol. 50(19): 10644-10652.

Recatalá, L., Sánchez, J., Arbelo, C. \& Sacristán, D. 2010. Testing the validity of a $\mathrm{Cd}$ soil quality standard in representative Mediterranean agricultural soils under an accumulator crop. Sci. Total Environ. 409(1): 9-18.

Shao, Y., Wang, J., Chen, X. \& Wu, Y.N. 2014. The consolidation of food contaminants standards in China. Food Control 43: 213-216.

Zhao, F.J., Ma, Y.B., Zhu, Y.G., Tang, Z. \& McGrath, S.P. 2015. Soil contamination in China: current status and mitigation strategies. Environ. Sci. Technol. 49(2): $750-759$. 